\title{
Cross-channel distribution of small fish in tropical and subtropical coastal wetlands is trophic-, taxonomic-, and wetland depth-dependent
}

\author{
Ross Johnston*, Marcus Sheaves
}

School of Marine and Tropical Biology, James Cook University, Townsville, Queensland 4811, Australia

\begin{abstract}
Although understanding the spatial distribution of fish is crucial to effective management of estuaries and coastal wetlands, there has been little systematic study of fish distribution at the cross-sectional scale in tropical estuaries. We tested the generality of a model for the cross-channel distribution of small fish ( $<200 \mathrm{~mm}$ fork length), extrapolated from temperate studies, for tropical and sub-tropical estuaries and coastal wetlands. We used cast nets, which could be deployed across a wide variety of habitats, to directly compare fish abundance between channel edges and adjacent mid-channel areas across a variety of coastal floodplain wetlands, including fully estuarine, brackish and freshwater sites. Cross-channel distribution of fish was more complex than the original model suggested. The original model reliably predicted the distribution of benthic feeding fish in most locations when mean mid-channel depths were $>0.83 \mathrm{~m}$. However, the model was less effective for predicting distributions of benthic feeders in shallow locations or in locations lacking shallow water edges. In those locations there was little difference in the abundance of fish between edges and midchannels. Distributions of planktivores and detritivores in estuarine and brackish areas were not consistently predicted by either of these models, but varied unpredictably over space and time. An additional model was needed for detritivores in freshwater wetlands with highest abundances in deeper mid-channel areas.
\end{abstract}

KEY WORDS: Fish distribution - Tropical estuary $\cdot$ Coastal wetlands $\cdot$ Distribution models $\cdot$ Habitat Depth

- Resale or republication not permitted without written consent of the publisher

\section{INTRODUCTION}

Understanding the spatial distribution of fish is crucial for effective management of estuaries and wetlands (Cross \& McInerny 2005, Isaak \& Thurow 2006). This allows efficient allocation of sampling to represent the range of species and habitat types present, providing for more reliable estimates of population parameters. Moreover, because distribution is frequently inter-related with trophic function (Sheaves \& Molony 2000), a clear knowledge of distribution enhances understanding of energy flows through and within systems. Knowing how fish are distributed in space and time is also crucial in interpreting and explaining the processes that influence the use of estu- aries and wetland habitats. For example, predation and depth may influence habitat use; it is often suggested that small fish use shallow estuarine habitats because they exclude large piscivorous fish (Paterson \& Whitfield 2000).

In temperate estuaries and wetland pools, small fish (<200 mm fork length [FL]) utilise shallow-edge habitats extensively. Explicit deep vs. shallow habitat studies, using comparable sampling gears across habitats, have found fewer small fish in deeper water (Miltner et al. 1995, Gibson et al. 2002), although the pattern does not necessarily extend to all species (Gibson et al. 2002). Additionally, McIvor \& Odum (1988) reported lower numbers of small fish on steeper-angled, deep erosional banks than on shallow, lower-angled accret- 
ing banks. When combined, the results of these studies suggest a simple conceptual model for the distribution of small fish in temperate estuaries (Fig. 1), with relatively high abundances of fish using low-angled, shallow edge habitats, a lower proportion of the fish assemblage using steeper banks and lowest abundances in adjacent, deeper mid-channel areas.

While the limited literature from Australian tropical and sub-tropical coastal wetlands suggests a parallel situation to that in temperate systems, with a large majority of small fish along shallow edge habitats (Blaber et al. 1989, Robertson \& Duke 1990), the evidence is not strong. This is because explicit comparisons between shallow and deep habitats are lacking. Most Australian studies (Blaber 1980, Blaber et al. 1985, Robertson \& Duke 1987, 1990, Coles et al. 1993, Sheaves 2006) have concentrated on tidal estuaries and focused on comparisons among shallow habitats, thus providing no information about the use of deeper habitats by small fish. In fact, in targeting small juvenile fish in shallow portions of the estuary, the influential study of Robertson \& Duke (1990) explicitly excluded deeper waters. Fish abundance in deeper estuarine habitats was examined by Sheaves (1992, 1996) but those studies were focused on larger fish and provided little information about the occurrence of small fish in deep water. However, those studies indicated indicate that abundances of larger fish were concentrated in edge habitats with relatively low

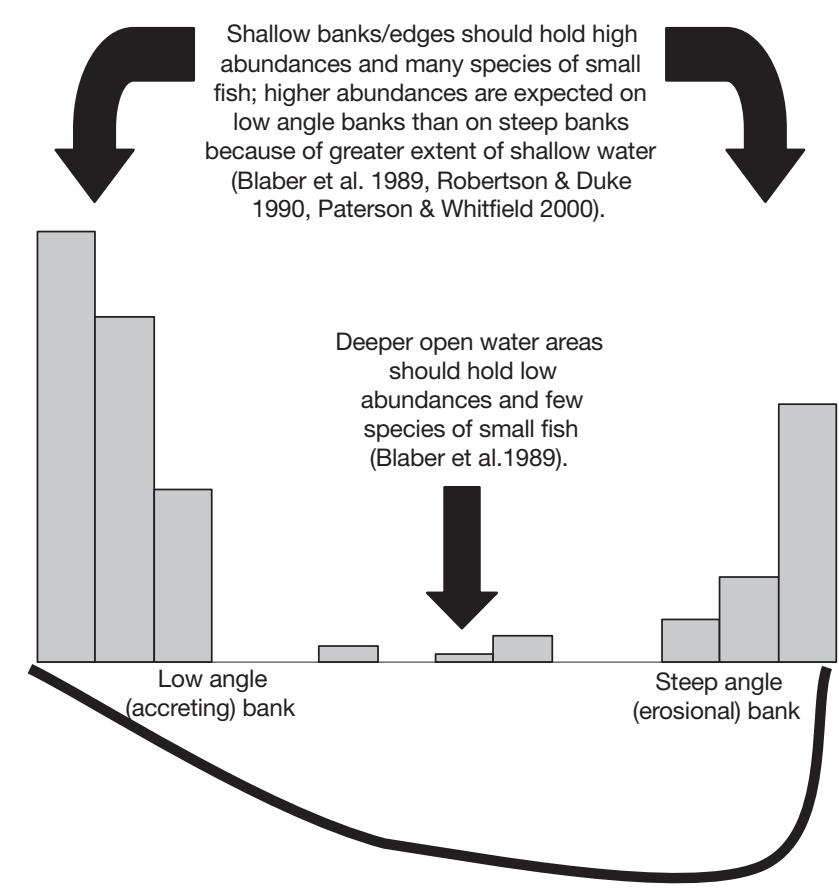

Fig. 1. Initial conceptual model of the spatial distribution of small fish along a cross-channel profile abundances of fish in deeper mid-channel areas, a parallel pattern to the implied distribution of small fishes (Fig. 1). Blaber et al. (1989) examined a range of habitats that included both shallow and deeper habitats in the Embley estuary in northern Australia and reported high numbers of small fish in shallow habitats, concluding there were few small fish in channels (deeper habitat). However, different gears were used in different habitats, with deep water habitats only sampled with gear unsuitable for collecting small fish (gill nets, smallest mesh size $50 \mathrm{~mm}$ ).

The lack of definitive information about spatial distributions of Australian fish extends beyond tidal estuaries to encompass other tropical and subtropical coastal floodplain wetlands such as floodplain pools, lakes and lagoons, temporarily flooded lowlands, and palustrine habitats, that until recently (e.g. Sheaves et al. 2006, 2007a) have received little research focus. These include ephemeral or permanent bodies of water with conditions ranging from freshwater to hypersaline depending on the extent and frequency of connection to river and estuary systems (Sheaves et al. 2006, 2007a,b). As in estuaries, shallow and/or edge habitats have been the primary focus of research in Australian coastal floodplain wetlands. Consequently there is little understanding of the spatial distribution patterns of wetland fish at varying many scales (Pusey et al. 2004).

Although the lack of specific distributional studies means the validity of the temperate distributional model cannot be evaluated in a tropical context, the idea of concentration of small fish in shallow water habitats fits well with current theoretical understandings of processes thought to structure tropical and subtropical wetland fish faunas. Prominent among these are ideas that shallow water provides reduced predation (Ruiz et al. 1993, Paterson \& Whitfield 2000, but see Sheaves 2001, Baker \& Sheaves 2005) and access to complex mangrove habitats (Robertson \& Blaber 1992), thereby enhancing nursery ground value (Sheaves 2005). Unfortunately, the lack of well supported distributional models limits our ability to develop and examine such ideas. Consequently, developing a more complete understanding of the distribution of fish in tropical estuaries and wetlands is an important research priority, both as an end in itself, and as a crucial step in investigating the processes that underpin important ecological functions. The present study tests the generality of the temperate small-fish distribution model for tropical and sub-tropical systems by directly comparing fish abundance between channel edges and adjacent mid-channel, deep-water areas across a variety of coastal floodplain wetlands including fully estuarine, brackish and freshwater sites. 


\section{MATERIALS AND METHODS}

Site descriptions. Data were collected from 13 locations: Deluge Inlet, Victoria, Barramundi and Stuart Creeks, Curralea and Paradise Lakes, and Aplin's and Black Weirs in tropical north Queensland; and 12 Mile, Gonong and Munduran Creeks and Frogmore and Woolwash Lagoons just outside the tropics in central Queensland, between July 2001 and March 2006 (Table 1, Fig. 2). Four of the freshwater systems are either disconnected from estuaries by weirs (Aplin's and Black) or only connect to downstream estuary areas during freshwater flows (Frogmore and Woolwash). Gonong and Munduran Creeks and Curralea and Paradise Lakes have frequent but restricted tidal connection to downstream areas (natural rock bars and tide gates, respectively) and alternate between freshwater and hypersaline conditions depending on the frequency and volume of freshwater input. There was little variation from normal seawater salinities $(36 \%)$ at these locations throughout the sampling period. The sampling site in 12 Mile Creek has infrequent tidal connection to downstream areas of the estuary because extensive salt pans act as barri- ers to all but a few of the highest spring tides each year. Consequently, the sampling area in 12 Mile Creek was hyposaline throughout the study, except in May 2005 when it reached 36\%. The remaining locations were all tidally influenced and fluctuated around seawater salinities throughout the study period. All locations influenced by tides have macroand semi-diurnal tidal regimes, although restrictions to tidal flow into 12 Mile, Gonong and Munduran Creeks and Curralea and Paradise Lakes moderate tidal influence to range of less than $1 \mathrm{~m}$.

The cross-channel profile of each sampling location can be broadly categorised into one of 2 profile types (Fig. 3). Locations with heterogeneous profiles (HeP) possessed a cross-channel profile with 2 distinctly different edge morphologies (Fig. 3a), leading to an obvious question about differential use of those edges by fishes. Consequently, to allow investigations of differences in fish abundance between the 2 bank types, they were analysed independently from locations with similar or homogeneous bank profiles (HoP). In contrast, there was no reason or basis for differentiating between edges among HoP locations, and any edge categorization would lead to arbitrary coding. There-

Table 1. Types and physical descriptions of coastal wetlands sampled, sampling times and number of samples collected for each of the 13 locations. Wetland types: $\mathrm{fw}=$ isolated freshwater pool, te = tidal estuary, ter $=$ pool with restricted tidal access. Habitat types: up = urban parkland, $\mathrm{r}=$ residential and/or commercial properties, $\mathrm{ds}=$ dry sclerophyll forest, $\mathrm{p}=$ pastures, $\mathrm{m}=\mathrm{mangrove}$ forest, $\mathrm{sp}=$ salt pan. Dimensions of sampling locations represent site (pool) at full, non-flood water levels for freshwater and restricted tidal access wetlands; for tidal estuaries lengths were measured from the mouth to the upstream extent of tidal influence and widths were measured at the estuary mouth

\begin{tabular}{|c|c|c|c|c|}
\hline $\begin{array}{l}\text { Location } \\
\text { (wetland type) }\end{array}$ & $\begin{array}{l}\text { Predominant } \\
\text { adjacent } \\
\text { habitat types }\end{array}$ & $\begin{array}{c}\text { Estuary/wetland } \\
\text { length } \times \text { width }\end{array}$ & $\begin{array}{c}\text { Depth } \\
\text { iid-channel (m) } \\
\text { Mean (SE) }\end{array}$ & Sampling date (no. of nets) \\
\hline \multicolumn{5}{|l|}{ Heterogeneous profile } \\
\hline \multicolumn{5}{|l|}{ Cast nets } \\
\hline Victoria Creek (te) & $\mathrm{m}$ & $14.7 \mathrm{~km} \times 420 \mathrm{~m}$ & $3.14(0.25)$ & Jun (60) 2005 \\
\hline Deluge Inlet (te) & $\mathrm{m}$ & $9.6 \mathrm{~km} \times 550 \mathrm{~m}$ & $2.64(0.10)$ & Jul (24), Aug (96) 2001; Apr (36), Jul (120) 2005 \\
\hline Paradise Lake (ter) & up, r & $960 \mathrm{~m} \times 110 \mathrm{~m}$ & $1.64(0.02)$ & $\begin{array}{l}\text { Nov (60) 2004; Mar (60), May (72), Nov (60) 2005; } \\
\text { Mar (24), Dec (36) } 2006\end{array}$ \\
\hline Stuart Creek (te) & $\mathrm{m}, \mathrm{sp}$ & $6.4 \mathrm{~km} \times 60 \mathrm{~m}$ & $0.83(0.03)$ & Jun (72), Jul (192) 2002 \\
\hline Munduran Creek (ter) & ds & $350 \mathrm{~m} \times 18 \mathrm{~m}$ & $0.75(0.05)$ & Nov (39) 2004; Feb (48), May (54) 2005 \\
\hline Gonong Creek (ter) & ds & $450 \mathrm{~m} \times 20 \mathrm{~m}$ & $0.72(0.05)$ & Nov (51) 2004; Feb (48), May (48) 2005 \\
\hline \multicolumn{5}{|l|}{ Danish seine nets } \\
\hline Victoria Creek (te) & $\mathrm{m}$ & $14.7 \mathrm{~km} \times 420 \mathrm{~m}$ & $2.53(0.25)$ & Jun (8), Jul (8) 2002 \\
\hline Barramundi Creek (te) & $\mathrm{m}, \mathrm{sp}$ & $16.5 \mathrm{~km} \times 300 \mathrm{~m}$ & $2.0(0.24)$ & Nov (12) 2002 \\
\hline \multicolumn{5}{|l|}{ Homogeneous profile } \\
\hline \multicolumn{5}{|l|}{ Cast nets } \\
\hline Black Weir (fw) & up, ds & $7 \mathrm{~km} \times 90 \mathrm{~m}$ & $4.52(0.17)$ & Oct (72), Nov (72) 2005 \\
\hline Aplin's Weir (fw) & up & $4.3 \mathrm{~km} \times 130 \mathrm{~m}$ & $3.75(0.08)$ & $\begin{array}{l}\text { Jan (126), Mar (99), May (84), Jun (108); Oct (81), } \\
\text { Nov (63) 2005; Mar (63) } 2006\end{array}$ \\
\hline Curralea Lake & up, $\mathrm{r}$ & $460 \mathrm{~m} \times 120 \mathrm{~m}$ & $2.37(0.03)$ & $\begin{array}{l}\text { Nov (84) 2004; Mar (111), May (87), Nov }(63,63) \text {, } \\
\text { Dec }(63,60) \text { 2005; Mar (60), Dec (39) } 2006\end{array}$ \\
\hline 12 Mile Creek (ter) & $\mathrm{p}$ & $800 \mathrm{~m} \times 15 \mathrm{~m}$ & $2.26(0.08)$ & Nov (78) 2004; Feb (96), May (60) 2005 \\
\hline Frogmore Lagoon (fw) & $\mathrm{p}$ & $2 \mathrm{~km} \times 80 \mathrm{~m}$ & $2.09(0.06)$ & July (72), Nov (72) 2004; Feb (72), May (36) 2005 \\
\hline Woolwash Lagoon (fw) & $\mathrm{p}$ & $2 \mathrm{~km} \times 80 \mathrm{~m}$ & $0.92(0.05)$ & Feb (66) 2005 \\
\hline
\end{tabular}




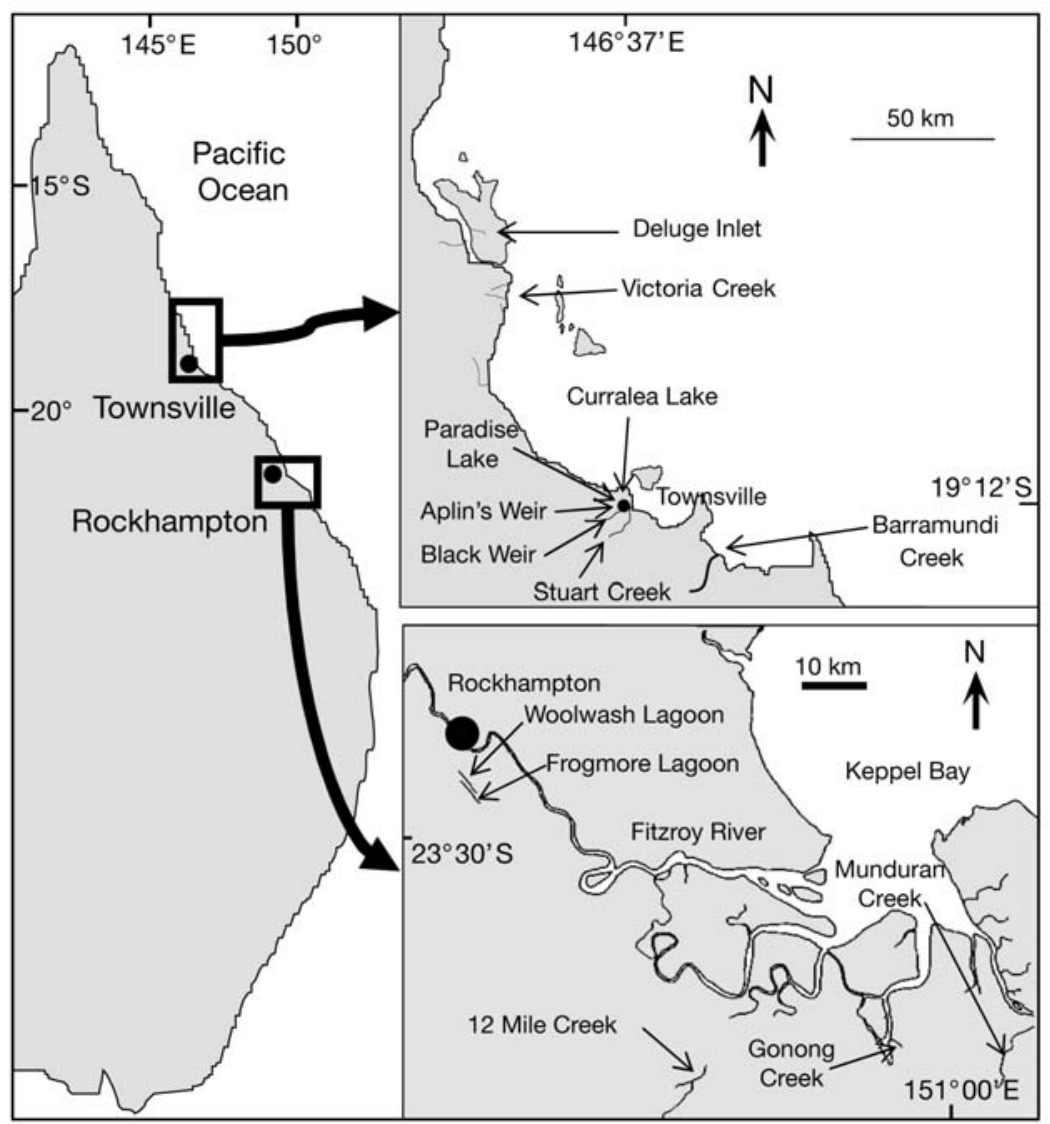

Fig. 2. Study locations on the north-eastern coast of Australia fore, if those locations were analysed together, overall comparisons between banks would be confounded with the arbitrary coding (if banks were coded A \& B, a bank coded A at one site would have no logical relationship to similarly coded banks at other locations). To overcome this problem, each of these 6 locations was analysed separately and distribution patterns compared subsequent to analyses. The inclusion of HoP locations does not provide a direct test of the literature-based distribution model because HoP locations lack clear differentiation between banks; however, their inclusion allows understanding of cross-channel distribution of fish to be extended to other profile types.

Sampling. Fully estuarine samples were collected in the lower reaches $(0$ to $7 \mathrm{~km}$ from mouth) of Deluge Inlet and Victoria and Stuart Creeks; brackish samples from pools at the upper extent of tidal incursion in Gonong (3 km from mouth), Munduran (5 km from mouth) and 12 Mile (4 km from mouth) Creeks, and from the entire length of Curralea and Paradise Lakes; and freshwater samples from the downstream half of Black Weir and the entire lengths of a) Heterogenous bank profile $(\mathrm{HeP})$

(slope one side $<30^{\circ}$ ) (slope one side $>50^{\circ}$ )

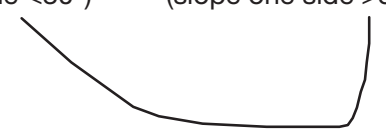

Deluge Inlet, Stuart Ck, Gonong Ck, Munduran Ck,Victoria Ck, Paradise Lake, Barramundi Ck

b) Homogeneous bank profiles (HoP)

Steep sided basin

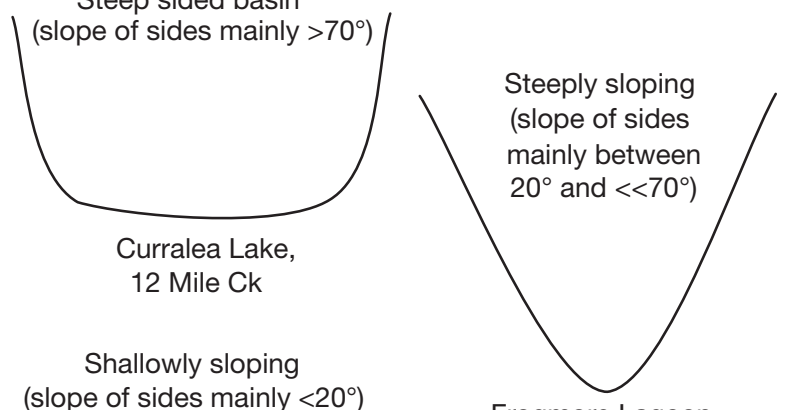
(slope of sides mainly $<20^{\circ}$ )

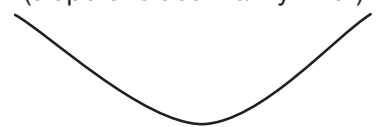

Frogmore Lagoon, Aplin's Weir, Black Weir Aplin's Weir, and Frogmore and Woolwash Lagoons. Data were collected in estuarine locations during the bottom half of spring tides when mangrove forests were not flooded, making fish more accessible to sampling gears (Johnston \& Sheaves 2007). Pools in Gonong, Munduran and 12 Mile Creeks were sampled when disconnected from the rest of the estuary, essentially low tide for these locations.

Because the aim of the study was to test the generality of the distribution model regardless of location or time, 12 locations were sampled haphazardly through time with cast nets, with repeated sampling in 10 of the locations for a total of 3150 net samples from 46 individual sampling occasions (Table 1 ).

Cast nets (18 mm monofilament mesh, $4.58 \mathrm{~m}$ diameter) were used to sample fish from 3 cross-channel positions: (1) as close as possible to one edge (e.g. low-

Fig. 3. Cross-channel profiles of the different sampling locations. (a) Heterogeneous bank profiles have clear differences in edge slope. (b) Homogeneous bank profiles lack clear differences. Deep water is accessible at both edges in steep-sided basins and one edge in sinuous estuary profiles. Shallowly sloping and steeply sloping profiles, and $<30^{\circ}$ edges in sinuous estuary profiles have clear differences in depths between edges and mid-channel 
angle banks in HeP locations); (2) from the adjacent mid-stream areas (approximately halfway to the opposite bank); and (3) as close as possible to the opposite bank (e.g. steep-angle banks in HeP locations). Cast nets were used because they allowed the collection of a large number of discrete samples from each of the 3 habitats and could be deployed equivalently in each habitat (Sheaves \& Johnston 2006a, Stevens et al. 2006, Johnston et al. 2007). To minimise disturbance all netting was conducted from a $3 \mathrm{~m}$ aluminium dinghy powered by an electric outboard motor. Cast net samples were not used if the net became entangled on obstacles, or if the spread (area) of the net when thrown did not achieve an estimated $85 \%$ of total spread. Theoretically, the maximum sampling area for the cast nets was $14.45 \mathrm{~m}^{2}$, but measurements from net throws on land indicated actual sampling area (total spread) was considerably less than this but not highly variable (mean area of net throw $=7.35 \mathrm{~m}^{2}[\mathrm{SE}=0.40, \mathrm{n}=50]$ ).

Danish seine nets (10 $\mathrm{m}$ long, $3 \mathrm{~m}$ drop, $18 \mathrm{~mm}$ mesh) were used to validate the patterns observed in the cast-net data. These seines (DAFF) were used as validating devices, rather than the principal sampling gear because they were slow to deploy and produced relatively little data per unit effort. Additionally, obstructions such as fallen timber prevented deployment of Danish seine nets on steep edges, so their use was restricted to mid-stream and low-angle edges. Danish seine nets are one of the only encircling gears besides cast nets that can be successfully deployed and retrieved wholly within mid-channel and shallow edge areas of an estuary. Danish seine nets were deployed perpendicular to shorelines, and used when mid-channel water depth was $3 \mathrm{~m}$ or less. The ends of the nets were fitted with $40 \mathrm{~m}$ haul lines used to drag the net forwards using a single boat until the net was completely closed and all fish were trapped in the cod end. The net was then lifted into the boat for sorting. Thus, like cast nets they sampled the entire water column, albeit in a different manner. Danish seine samples were collected on 2 occasions from Victoria Creek and once from Barramundi Creek (Table 1, Fig. 2).

Fish were identified to species and counted in the field, then released as quickly as possible. A subsample of catches was measured and weighed prior to release to enable biomass to be estimated.

Data analyses. Species-level data were typical of those from tropical estuary fish assemblages, with a few species dominating numbers (Sheaves 2006) and most species having insufficient representation for reliable analysis. However, 11 species occurred frequently enough in cast net catches from some locations (in at least $5 \%$ of nets) to allow species-specific analysis for those locations (Table 2). To enable the use of a greater quantity of the data and inclusion of all sites in

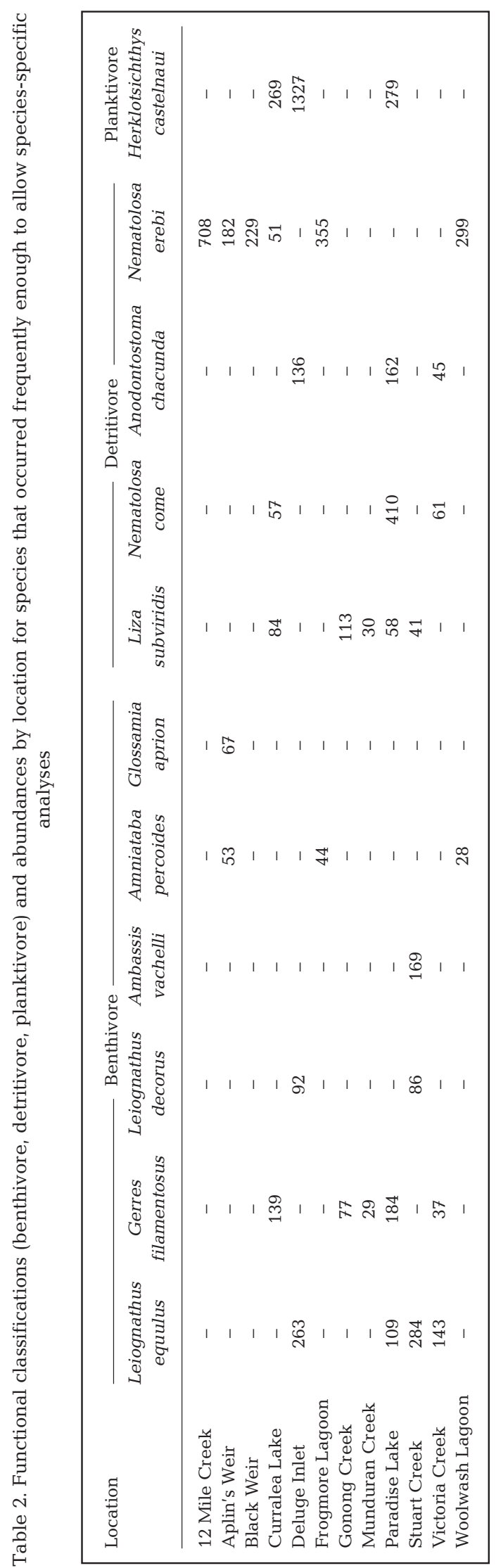


analysis, fish were classified into trophic groups and analysed using total group abundance from individual nets for each cross-channel position. Trophic classification effectively groups functionally similar species together, reducing the analytical difficulties that would be encountered in analyzing the more uncommon fish at a species level. Trophic groups were defined based on published dietary information (Wilson \& Sheaves 2001, Pusey et al. 2004, Sheaves \& Johnston 2006b). Three trophic groups occurred in at least $5 \%$ of cast net samples, providing sufficient data for analysis: (1) benthivores: feed on benthic prey, mainly infaunal and epifaunal invertebrates; (2) detritivores: feed principally on decomposing organic material; (3) planktivores: feed principally on micro-invertebrates in the water column. There was only sufficient Danish seine net data for analysis of the benthivore group.

Abundance data were 4 th root transformed to limit the influence of occasional nets with high abundances before analysis using univariate classification and regression trees (CARTs) (De'ath \& Fabricius 2000, De'ath 2002). Response variables were abundances of fish per net. Independent variables for HeP locations were cross-channel position (Low, Mid and Steep), location $\times$ trip, and mean mid-channel depth. Independent variables for HoP locations were: Edge, Mid and OpEdge (opposite edge), mean mid-channel depth, and trip. Average mid-channel depth for each sampling day was calculated as the mean of depths recorded at each mid-channel net deployment.

The data set featured a large number of zeros, a common problem that severely limits analytical options (McCune \& Grace 2002). However, CARTs are ideally suited to such problem data (De'ath \& Fabricius 2000, McCune \& Grace 2002). A 'tree' is constructed by making a series of mutually exclusive binary splits, with the objective of producing subsets that are as internally homogeneous as possible. After the initial data split, the process is repeated for each subset until subsets can no longer be split (i.e. are completely homogeneous under the splitting protocols used). The relative importance of each independent variable is determined by the level in the tree at which associated split(s) occur. Thus the first split in the tree is most 'important' in terms of accounting for overall variability with subsequent splits of increasingly lower importance. Any factors not represented in final tree models were not influential in the model. With a continuous response variable (regression tree) split selection is based on minimising within-group sum-of-squared residual deviation of the resultant groups. Complete trees are normally too large to be useful general models, so trees are 'pruned' to the required size (De'ath \& Fabricius 2000). The 1-SE tree models (the smallest tree with cross validation error within $1 \mathrm{SE}$ of that of the tree with the minimum cross-validation error) were used in most instances, because this generally produces a parsimonious, useful model (Breiman et al. 1984).

Although patterns in biomass were also investigated, interpretation focuses on abundance data. Biomass data were analysed using the same approach as abundance data, and, with minor exceptions, produced the same patterns. However, because of the influence of a few large individuals in particular samples, biomass occasionally produced more complex CART models that contained additional location/trip splits (which provided no information on differences among crosschannel positions). In most cases the distribution patterns were stronger using biomass, so the presentation of abundance data generally provides a conservative view of the strength of distribution patterns.

\section{RESULTS}

A total of 8578 fish from 76 species were recorded during the study. Those included: 8311 fish from 73 species in 3150 cast net samples and 267 fish from 24 species in 28 Danish seine net samples. No species captured in Danish seine nets was absent or poorly represented in cast nets.

\section{Benthic feeders: trophic group level}

The cross-channel distributions of benthic-feeding fish assemblages were generally in accord with the literature-based model, with higher abundances recorded from edges than mid-channel areas for the majority of sites. cross-channel position was the most important explanatory variable in all $6 \mathrm{HeP}$ estuary locations (in both cast net and Danish seine nets) (Fig. 4 left panels) and in 4 of the 6 HoP locations (cast net) (Figs. 5 \& 6 left panels). Cross-channel position also formed a major secondary split for Curralea Lake (following a primary split on trip) (Fig. 5a), while there was a minor split on cross-channel position at 12 Mile Creek where trip was the important variable (Fig. 5b left). Both edges held higher abundances of benthic feeding fish than mid-channels in the HeP estuaries (Fig. 4 right), for 3 of the 9 samples from Curralea Lake (Fig. 5a right) and all Aplin's Weir samples (Fig. 6b right). However, cross-channel position had no influence for the remaining Curralea Lake samples and only minor influence in 12 Mile Creek (Fig. 5b right). These 2 locations were the only steep-sided basins (Fig. 3b) in the study, thus outcomes should be interpreted cautiously. One edge held higher abundances than other cross-channel positions in Black Weir (Fig. 6a right), while abun- 


\section{a Castnet}

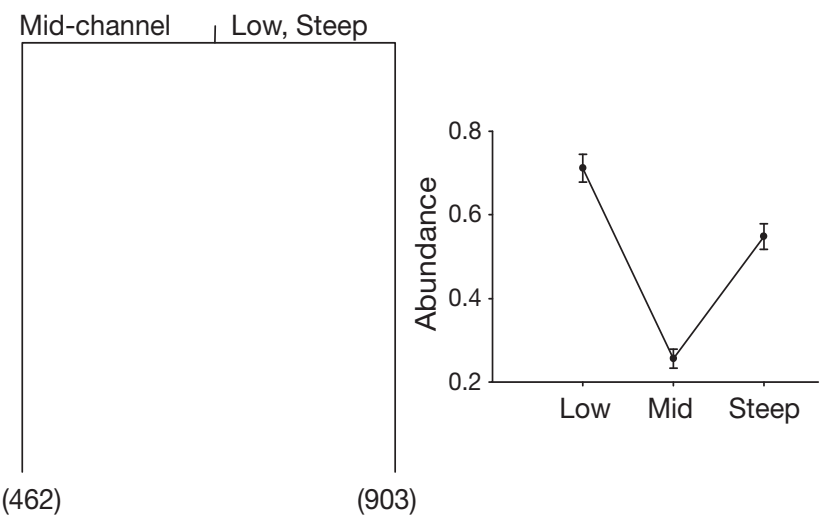

b Danish seine net

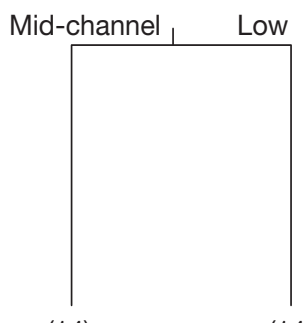

(14)

(14)

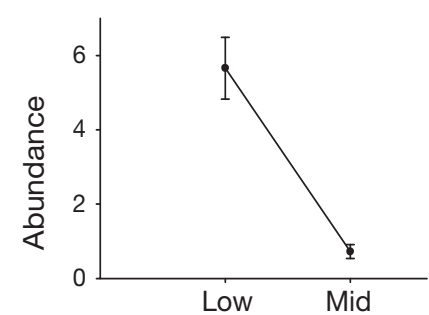

Fig. 4. Classification and regression trees (left panels) and distribution profiles of mean abundance per net (right panels) of the benthic-feeding fish assemblage in heterogeneous bank profiles for (a) cast net and (b) Danish seine net samples (steep banks were not sampled with Danish seine nets). Data are 4 th root transformed abundances $( \pm S E)$. Numbers in brackets at tree terminal nodes are sample size. Low: low angle bank, Mid: mid-channel, Steep: steep angle bank, E \& OpEdge: edge and opposite edge for homogeneous bank profiles. When abbreviated, locations and trips are designated by the first initial of the location and by month and year of the sample (e.g. PNov04 = Paradise Lake November 2004)

dances were higher in mid-channel and on one edge in Frogmore Lagoon (Fig. 6c right). In contrast, abundances were highest in mid-channel alone in Woolwash Lagoon (Fig. 6d right), the only location with a shallowly sloping profile (Fig. 3b). At the time of sampling Woolwash Lagoon was not only shallow (max. depth $1.4 \mathrm{~m}$, Table 1) but inhabited by large flocks of piscivorous, surface feeding birds (pelicans), a factor that may account for the strong association with the deeper midchannel habitats in that location.

\section{Benthic feeders: species-specific analyses}

There were sufficient data for species level analysis of 6 individual species of benthic feeding fish (Table 3). Univariate CART analyses indicated that patterns of
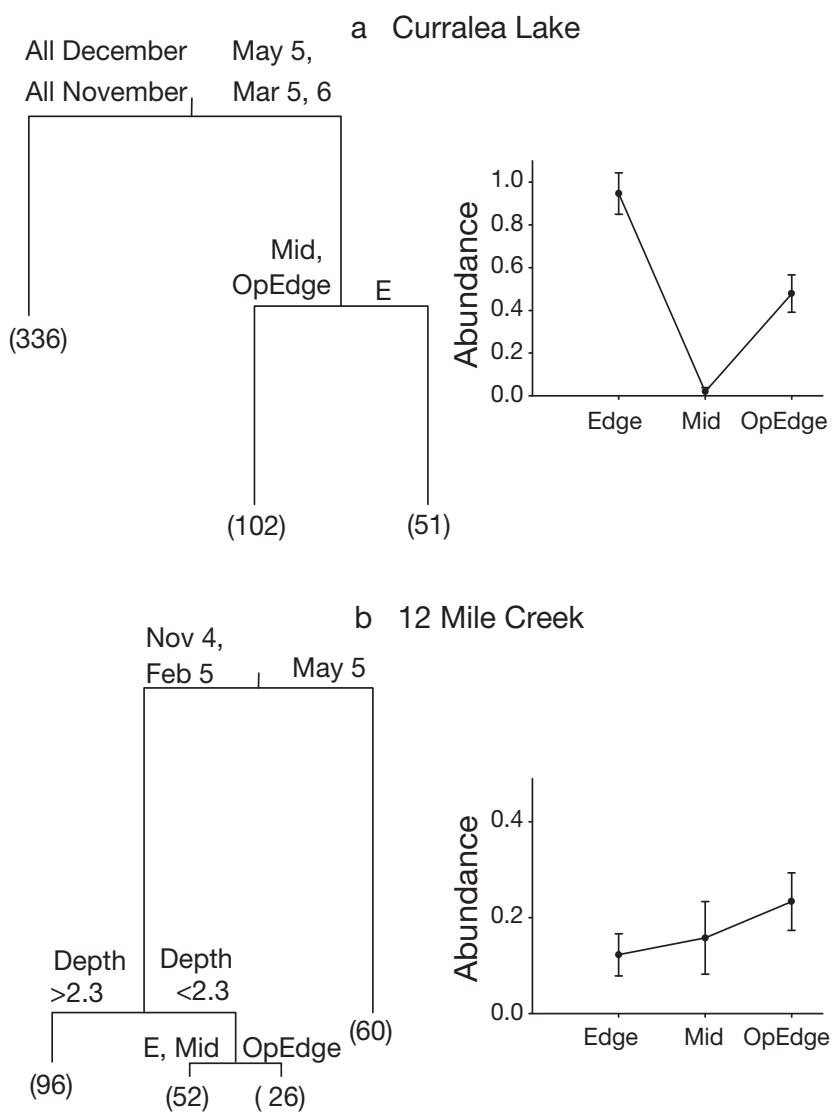

Fig. 5. As Fig. 4 for benthic-feeding fish assemblage in locations with homogeneous bank profiles, (a) Curralea Lake and (b) 12 Mile Creek. See Fig. 4 for abbreviations and further details

distribution for most of those closely matched the predicted pattern, with higher abundances in edge habitats than mid-channels for all 6 species in a majority of locations with sufficient data for analyses (Table 3). For HeP locations Leiognathus equulus and L. decorus were consistently less abundant in mid-channels than on one or both edges (Fig. $7 a, b)$. Location $\times$ trip was more important than position for Gerres filamentosus and Ambassis vachelli (Fig. 7c,d), however G. filamentosus abundances were higher at edges than in midchannel in Victoria Creek and Paradise Lake. Deviation from the predicted pattern for $G$. filamentosus was evident in the shallower locations of Gonong and Munduran Creeks (max. depths 1.9 and $1.4 \mathrm{~m}$, respectively) (Table 1, Fig. 7c). Cross-channel position had the strongest influence on all benthic species in the HoP locations (Table 3). G. filamentosus (Fig. 7e), Amniataba percoides (Fig. 7f) and Glossamia aprion (Fig. 7g) were more abundant on edges than in midchannel with one exception: A. percoides in Woolwash Lagoon were just as abundant in mid-channel as they were on one edge. 
Edge, a Black Weir

Mid-channel OpEdge

(96)

(48)

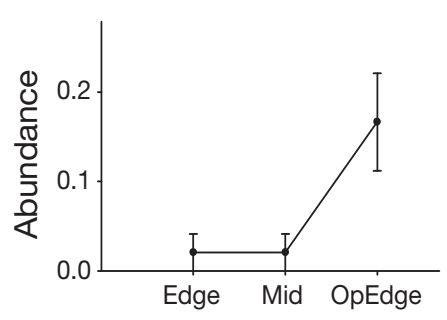

Edge,

b Aplin's Weir

\section{Mid-channel OpEdge}

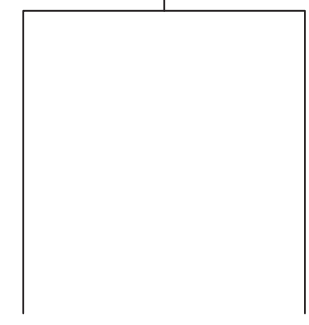

(180)

(387)

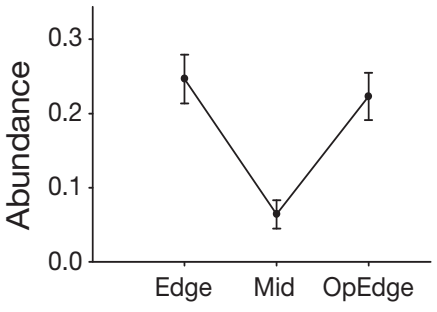

c Frogmore Lagoon
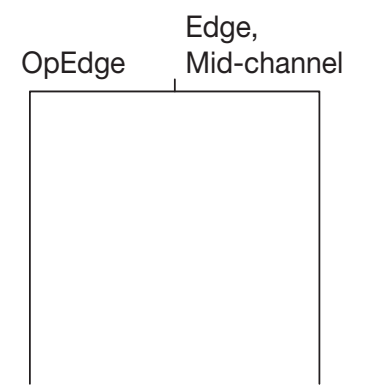

(72)

(144)
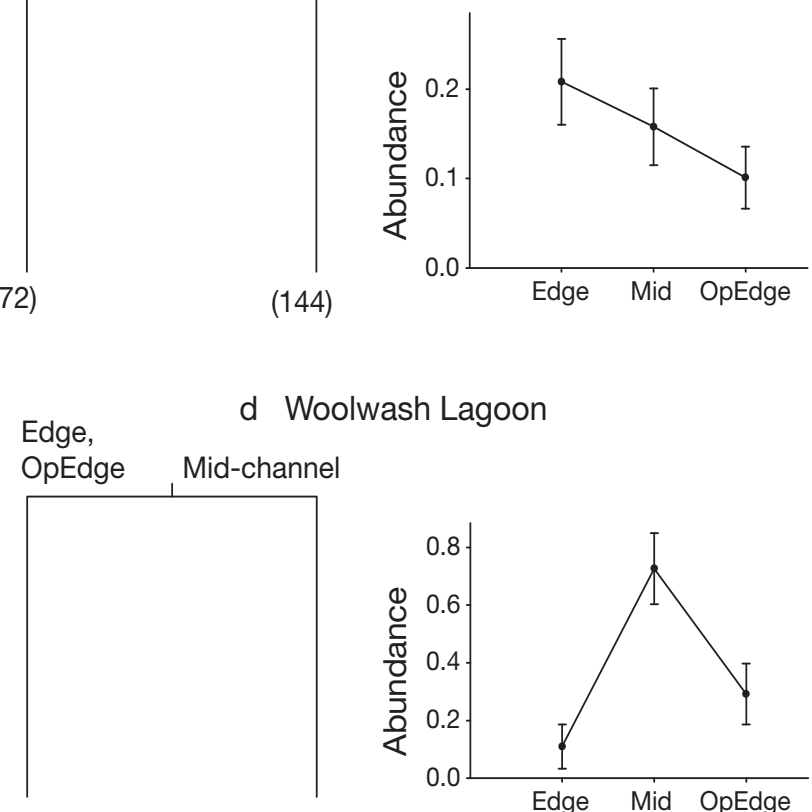

(44)

(22)

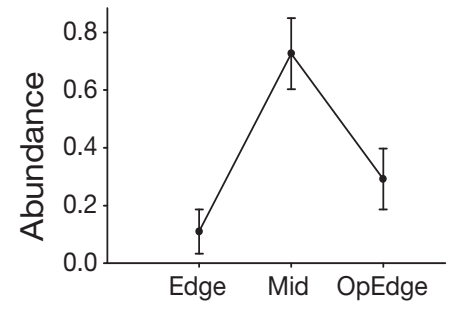

Fig. 6. As Fig. 4 for benthic-feeding fish assemblage in locations with homogeneous bank profiles, (a) Black Weir, (b) Aplin's Weir, (c) Frogmore Lagoon, (d) Woolwash Lagoon. See Fig. 4 for abbreviations and further details

\section{Plankton feeders: trophic group level}

The literature-based model did not reliably predict cross-channel distribution of planktivorous fishes for most HeP samples (Fig. 8a), although abundances of planktivores were higher on edges than in mid-channels in all samples from Deluge Inlet and 2 of the 9 samples from Paradise Lake. In Curralea Lake, the only HoP location with reasonable numbers of planktivores, distribution was influenced by season but not by cross-channel position (Table 3).

\section{Plankton feeders: species-specific analyses}

The cross-channel distribution of Herklotsichthys castelnaui, the only planktivore with sufficient data for species-level analysis, was not consistent among HeP locations (Table 3). However, in Deluge Inlet abundance of $H$. castelnaui was higher on edges than midchannel (Fig. 8b) and higher on steep edges than midchannel or low angle banks in Paradise Lake (Fig. 8c).

\section{Detritus feeders: trophic group level}

The literature-based model was not a reliable predictor of detritivore distribution. cross-channel position had little influence on the distribution of detritivores in HeP locations (Fig. 9a left). A tertiary split indicated that HeP mid-channels had fewer fish than edges in 5 of the 6 locations at particular times, however, the pattern was not consistent for all sampling occasions in any location. Among the HoP locations, cross-channel position had no influence in the steep-sided basins (12 Mile Creek and Curralea Lake), where trip was the overriding factor influencing abundances (Fig. 9b,c). In contrast, position had a strong effect in the 4 remaining HoP locations (Fig. 10). In those 4 freshwater locations the expected model was reversed with higher abundances in mid-channel than edge habitats.

\section{Detritus feeders: species analyses}

The distribution of detritivore species (Table 3, Fig. 11) was generally not in accordance with the literature-based model. Among the detritivores in $\mathrm{HeP}$ locations, Nematolosa come, Anodontostoma chacunda and Liza subviridis were primarily influenced by location and trip (Fig. 11a,b,c). There were only a few samples from Paradise Lake where abundances of $N$. come were higher on at least one edge than in midchannel. Most species in shallower HeP locations (Table 1) had similar abundances in all cross-channel 
Table 3. Univariate CART (classification and regression tree) analyses of individual species showing both primary and secondary splits. For splits on cross-channel position, position details of the high abundance (right hand) branch are provided. When there was a secondary position split following a primary split on trip, the number of sampling trips associated with the position split and the total number of trips are given in parentheses, i.e. $(2 / 6)=2$ trips in which position was important out of a possible 6 trips. $\mathrm{HeP}$ and HoP: heterogeneous and homogeneous profiles, resüectively

\begin{tabular}{|c|c|c|c|}
\hline Species & Location & Primary split & Secondary split(s) \\
\hline Benthic feeding group & HeP & & \\
\hline Leiognathus equulus & Deluge Inlet & Position-low, steep & Position-low \\
\hline L. equulus & Paradise Lake & Trip & Position-low, steep $(2 / 6)$ \\
\hline L. equulus & Stuart Creek & Position-low, steep & Position-low \\
\hline L. equulus & Victoria Creek & Position-low & Position-steep \\
\hline L. decorus & Deluge Inlet & Trip & Position-low, steep (1/3) \\
\hline L. decorus & Stuart Creek & Position-low, steep & Trip \\
\hline Gerres filamentosus & Paradise Lake & Position-low, steep & Position-low \\
\hline G. filamentosus & Victoria Creek & Position-low & - \\
\hline G. filamentosus & Gonong Creek & Trip & Position-mid, steep (2/3) \\
\hline G. filamentosus & Munduran Creek & Trip & Trip \\
\hline \multirow[t]{2}{*}{ Ambassis vachelli } & Stuart Creek & Trip & Position-low (1/2) \\
\hline & HoP & & \\
\hline Amniataba percoides & Frogmore Lagoon & Position-Edge, OpEdge & Trip \\
\hline A. percoides & Woolwash Lagoon & Position-OpEdge, mid & Position-mid \\
\hline A. percoides & Aplin's Weir & Position-Edge & Trip \\
\hline Glossamia aprion & Aplin's Weir & Trip & Position-Edge, OpEdge (6/7) \\
\hline Plankton feeding group & HeP & & \\
\hline Herklotsichthys castelnaui & Deluge Inlet & Position-low, steep & Trip \\
\hline \multirow[t]{2}{*}{ H. castelnaui } & Paradise Lake & Trip & Position-steep (4/6) \\
\hline & HoP & & \\
\hline H. castelnaui & Curralea Lake & Trip & Trip \\
\hline Detrital feeding group & HeP & & \\
\hline Nematolosa come & Victoria Creek & Position-low & - \\
\hline N. come & Paradise Lake & Trip & Position-low (3/6) \\
\hline Anodontostoma chacunda & Deluge Inlet & Position-low & Trip \\
\hline A. chacunda & Victoria Creek & Position-low & - \\
\hline A. chacunda & Paradise Lake & Trip & Position-steep, mid (2/6) \\
\hline Liza subviridis & Stuart Creek & Trip & $\begin{array}{l}\text { Position-low }(1 / 2), \text { Position-mid }(1 / 2) \\
\text { Position-low }(2 / 3)\end{array}$ \\
\hline L. subviridis & Gonong Creek & Trip & Trip \\
\hline L. subviridis & Munduran Creek & Trip & Trip \\
\hline \multirow[t]{2}{*}{ L. subviridis } & Paradise Lake & Position-low & \\
\hline & HoP & & Position-Edge, OpEdge (2/9) \\
\hline N. come & Curralea Lake & Trip & Position-Edge (4/9) \\
\hline L. subviridis & Curalea Lake & Trip & Position-mid $(2 / 9)$ \\
\hline N. erebi & Curralea Lake & Trip & Position-Edge, OpEdge (1/3) \\
\hline N. erebi & 12 Mile Creek & Trip & Trip \\
\hline N. erebi & Frogmore Lagoon & Position-mid & - \\
\hline N. erebi & Woolwash Lagoon & Position-mid & Trip \\
\hline N. erebi & Black Weir & Position-mid & Trip \\
\hline N. erebi & Aplin's Weir & Position-mid & \\
\hline
\end{tabular}

positions however there was a tendency for species in deeper locations ( $N$. come and L. subviridis [Paradise Lake], and $A$. chacunda [Deluge Inlet]) to have slightly elevated abundances associated with edges. N. come and L. subviridis were also present in Curralea Lake and as with the HeP locations abundances were primarily influenced by location $\times$ trip (Table 3 , Fig. 11d,e). For both species, abundances were higher on one edge than mid-channel for $33 \%$ (N. come) and
$44.4 \%$ (L. subviridis) of samples, but there was no differentiation between cross-channel positions for a majority of samples. The remaining species, N. erebi, had much higher abundances in mid-channel for most HoP locations (Fig. 11f). N. erebi (100\% of the detritivore catch in Aplin's and Black Weirs, Frogmore and Woolwash Lagoons; 96.2\% in 12 Mile Creek, and $21.6 \%$ in Curralea Lake), were strongly associated with mid-channel positions with 2 exceptions: the 2 


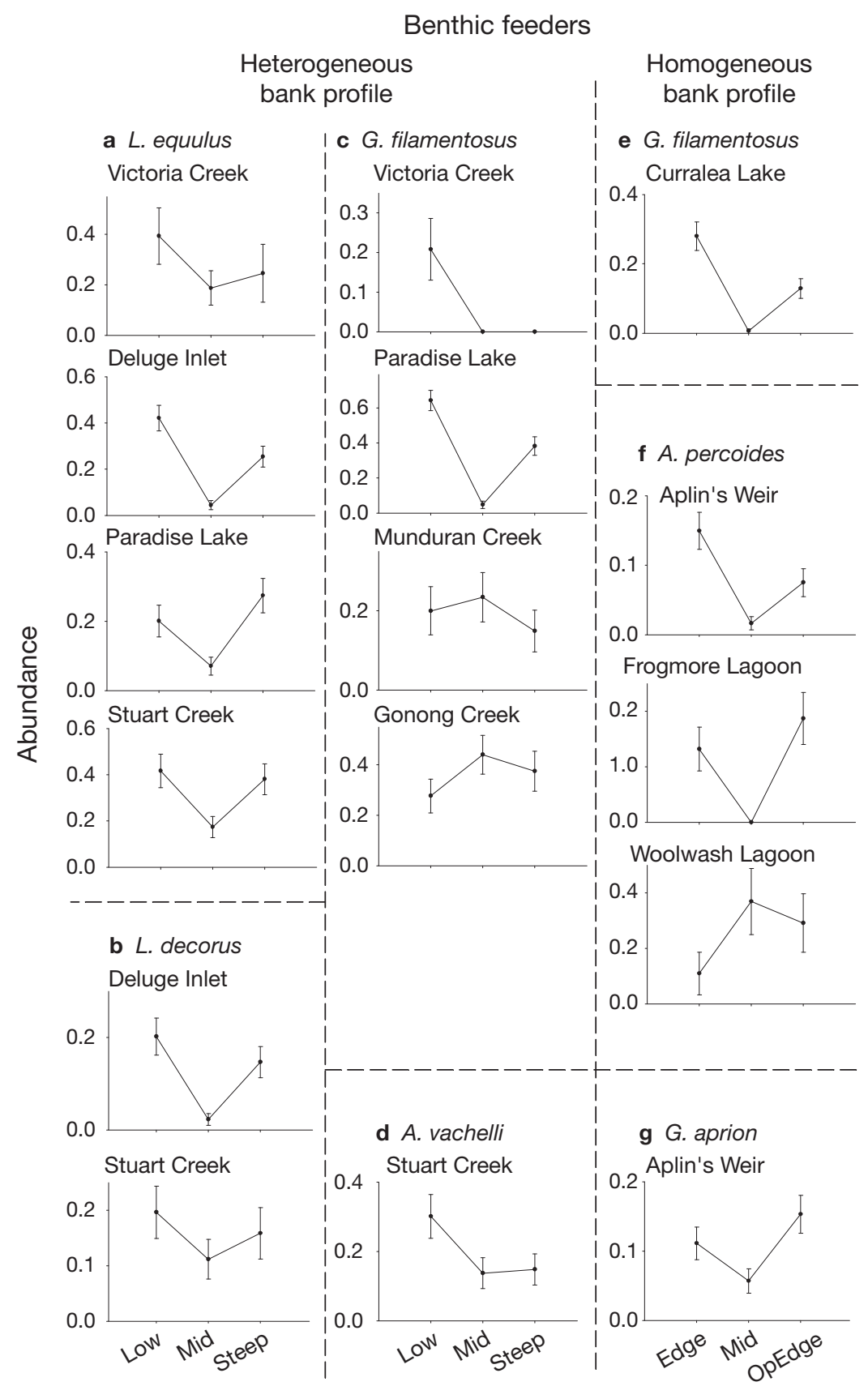

Fig. 7. Cross-channel distribution profiles of mean abundance per net (4th root transformed $\pm \mathrm{SE}$ ) for benthivore species in heterogeneous bank profiles (left \& center panels) and homogeneous bank profiles (right panels). For species represented in multiple locations, locations are ranked from deepest to shallowest based on average mid-channel depth. Heterogeneous bank profile: (a) Leiognathus equulus, (b) L. decorus, (c) Gerres filamentosus, (d) Ambassis vachelli; homogeneous bank profile: (e) G. filamentosus, (f) Amniataba percoides, (g) Glossamia aprion

steep-sided basins (Fig. 3b), 12 Mile Creek and Curralea Lake, where trip provided the primary split (Table 3) and there was little cross-channel difference in abundance.

\section{DISCUSSION}

The cross-channel distribution of fish across the diversity of coastal floodplain wetlands and tropical estuaries studied proved much more complex than suggested by the hypothesized model. The extent of concordance with the predicted model depended on mid-channel depth, as well as trophic role and species identity. In effect, 3 distinct versions of the model are necessary to comprehensively describe cross-channel distribution in the wetlands and estuaries of the study region (Fig. 12). The literature-based model predicted the distribution pattern of the benthic feeding fish assemblage reliably for most of the estuaries and coastal floodplain wetlands examined and consistently predicted the general distribution of benthic-feeding species for most locations when mean mid-channel depths were greater than $0.83 \mathrm{~m}$. Consequently, with one exception, the appropriate model for the benthic feeding fish assemblage when mid-channels were deep (model a, Fig. 12a) was identical to the predicted model. However, the model was less effective for predicting benthivore distributions in shallow locations and did not reliably represent benthivore distributions in 12 Mile Creek, a steep-sided basin with little difference in depths between edges and mid-channel. For these situations of shallow depths, or a profile lacking shallow water edges, a model with no strongly differentiated cross-channel pattern was more suitable (model b, Fig. 12b). Distribution patterns for planktivores and detritivores were not consistently predicted by the literature-based model but unpredictably varied between model a and model $b$. cross-channel distributions of those 2 functional groups and their respective species matched with the predicted patterns on occasion, however that pattern was not consistently repeated over time in any location. Among freshwater HoP locations, cross-channel distribution of detritivores was opposite to the predicted model so a model with high abundances in the deeper mid-channel areas (Model c, Fig. 12c) was generally more appropriate. It appears then that a more complex set of at 

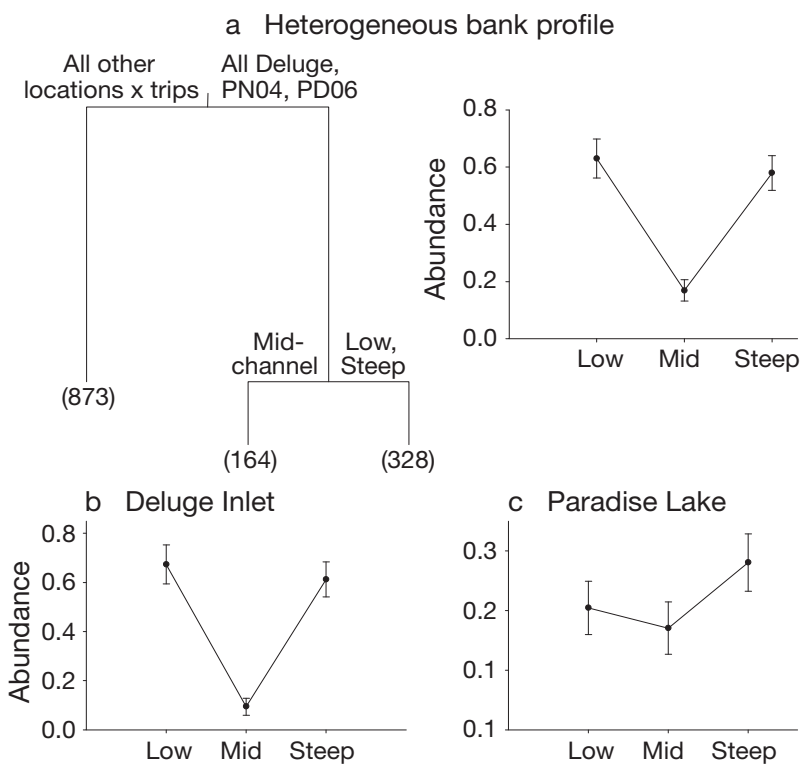

Fig. 8. As Fig. 4 for the plankton-feeding fish assemblage in (a) heterogeneous bank profiles. Species-specific distribution profiles of mean abundance per net for the planktivore Herklotsichthys castelnaui in (b) Deluge Inlet and (c) Paradise Lake. See Fig. 4 for abbreviations and further details.

\section{a Heterogeneous bank profiles}

DJul 05,

AllD, GNov 4, Feb 05 GMa 05, All M

AllM, PNov 05, Dec 06, PNov 04, Mar 05, 06,
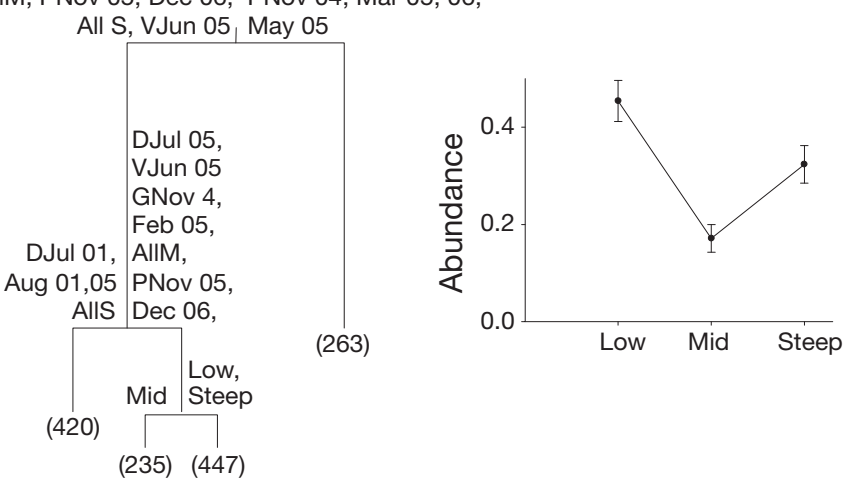

b 12 Mile Creek

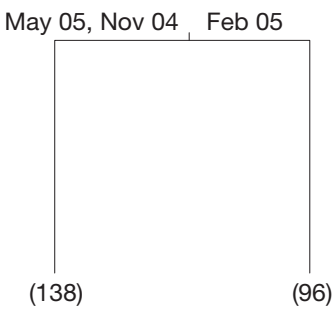

HoP locations

c Curralea Lake

All Dec, Mar 06 Mar 05, May 05, Nov $05 a, b$ Nov 04

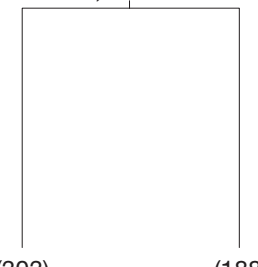

(303) least 3 models is necessary to describe the cross-channel distribution of fish in Australia's tropical estuaries and coastal floodplain wetlands.

\section{Model a: benthivores/deep mid-channel}

The distribution pattern of benthic- feeding fishes (Fig. 12a) was in accord with conclusions of both explicit (Miltner et al. 1995, Gibson et al. 2002) and implicit (McIvor \& Odum 1988) deep versus shallow water studies from temperate estuaries and supported the distribution patterns implied for Australian tropical estuaries (Blaber et al. 1989, Robertson \& Duke 1990, Sheaves 1992, 1996) and freshwater wetlands (Pusey et al. 2004). The extensive use of shallow water habitats by small fish has been used to support the idea that shallow edges provide a refuge from predation by excluding large predators (Cain \& Dean 1976, Reis \& Dean 1981, Morton et al. 1987, Ruiz et al. 1993, Paterson \& Whitfield 2000), however, even relatively large predators access shallow edges (Baker \& Sheaves 2005, Baker \& Sheaves 2006) where high abundances of benthic feeding fishes were recorded in the present study (Fig. 12a). In any case, shallow edge habitats are unlikely to exclude small piscivores and thus predatormediated mortality may not be substantially lower in edge habitats simply because of the exclusion of predators (Sheaves 2001, Baker \& Sheaves 2005). Moreover, the use of shallow edges may provide greater opportunity for avian predators. However, fish utilising shallow edge habitats may still be advantaged by the reduced number of directions from which a predator can attack, and it may be more difficult for larger mobile predators to take up a position to silhouette prey against the sky.

The refuge afforded by large areas of complex habitat, principally mangrove forests, has also been used to explain why there are high abundances of small fish in tropical estuaries (Robertson \& Blaber 1992) and by implication high abundances on channel edges. The situation seen for tidal estuaries in the present study suggests the benthic-feeding fish assemblage generally remained in shallow edges, tracking tidal fluctuations, when mangrove forests were not accessible. If availability of complex habitat is important, or alternative food resources are available in forests (Ellis \& Bell 2004), it is probable that small benthivores would migrate laterally into forests as they flood (Krumme et al. 2004). This appears to be the case because few benthivores are captured outside forests once flood tides provide (relatively shallow) access (R. Johnston \& M. Sheaves unpubl. data). Alternatively, McIvor \& Odum (1988) reported higher abundances of fish on shallow, low angle banks than on deeper, steep angle banks, and suggested lower current velocities on low-angle,

Fig. 9. As Fig. 4 for detritus-feeding fish assemblage in (a) heterogeneous bank profiles, and homogeneous bank profiles at

(b) 12 Mile Creek and (c) Curralea Lake. Data are from cast nets. See Fig. 4 for abbreviations and further details 


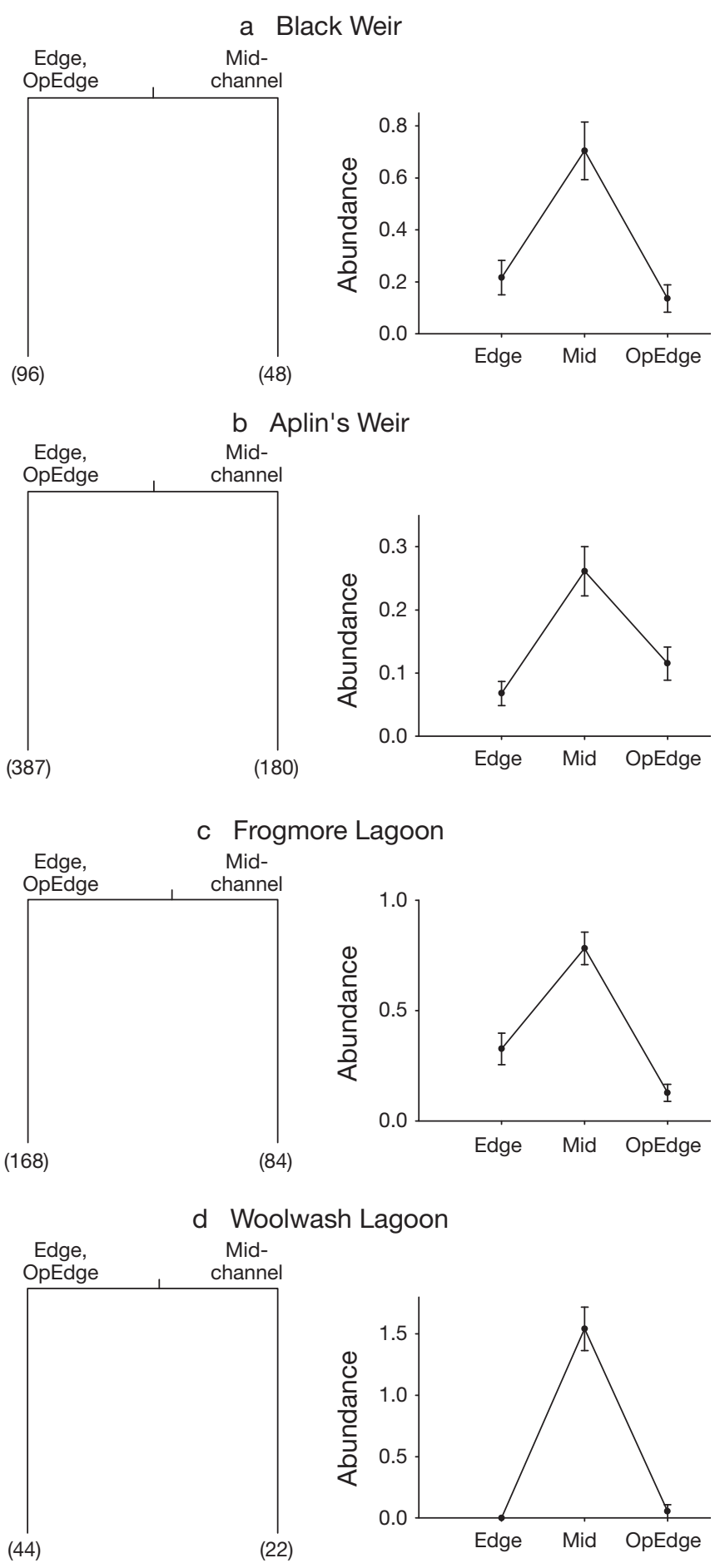

Fig. 10. As Fig. 4 for detritus-feeding fish assemblage in locations with homogeneous bank profiles, (a) Black Weir, (b) Aplin's Weir, (c) Frogmore Lagoon, (d) Woolwash Lagoon. See Fig. 4 for abbreviations and further details

accreting banks may provide an energetic advantage (Gaudin \& Sempeski 2001). However, many species from all trophic groups in the present study occurred in similar abundances on low and steep angle banks in sinuous estuaries suggesting energetic advantage was either not confined to low angle banks or not an overriding factor.

\section{Model b: benthivores/shallow mid-channel, planktivores \& detritivores/heterogeneous banks}

The existing literature had not predicted the broader and less predictable dispersal patterns of benthivores when mid-channel depths were shallow (mean midchannel depths $<0.83 \mathrm{~m}$.). Revised distribution models (Fig. 11) incorporate information to account for influence of mid-channel depth in the distribution of benthic fishes. Under shallow mid-channel conditions, functional groups and most species in those groups were more dispersed, and mid-channel frequently had abundances similar to edges (Fig. 11b). Although this could be interpreted to mean that depth was more important than position, the lack of differentiation could have developed because distances between edges and mid-stream areas were relatively short in shallower locations. There is a paucity of literature devoted to small tidal creeks (Mallin \& Lewitus 2004) and thus little opportunity to compare distributions among small systems or between large and small systems.

The distribution patterns of planktivores and detritivores (Fig. 11b) occasionally matched the predicted model but were not consistent among times or locations, possibly a reflection of high spatio-temporal variability in the abundance of these taxa. Alternatively, distribution of these functional groups may be related to food availability and consequently related to hydrodynamic factors. In systems with unrestricted tidal access, most of the deeper HeP locations, there was a trend towards higher abundances along edges where hydrodynamic features such as eddies and pressure points may deliver and/or accumulate plankton and detritus. Furthermore, mid-channel areas may be scoured by currents that leave relatively little food available for detritivores, a factor that may also account for low abundances of benthivores in the deeper HeP locations. However, higher abundances on edges were not consistent for detritivores at all $\mathrm{HeP}$ locations or for all detritivore species. Detritivore abundance was no higher on edges than in mid-channel in Victoria Creek for Anodontostoma chacunda or in Stuart Creek for Liza subviridis. The frequent recording of large numbers of planktivores and detritivores in deeper mid-channels also implies that the use of shallow water for protection from piscivorous fish is not a priority for these groups. 


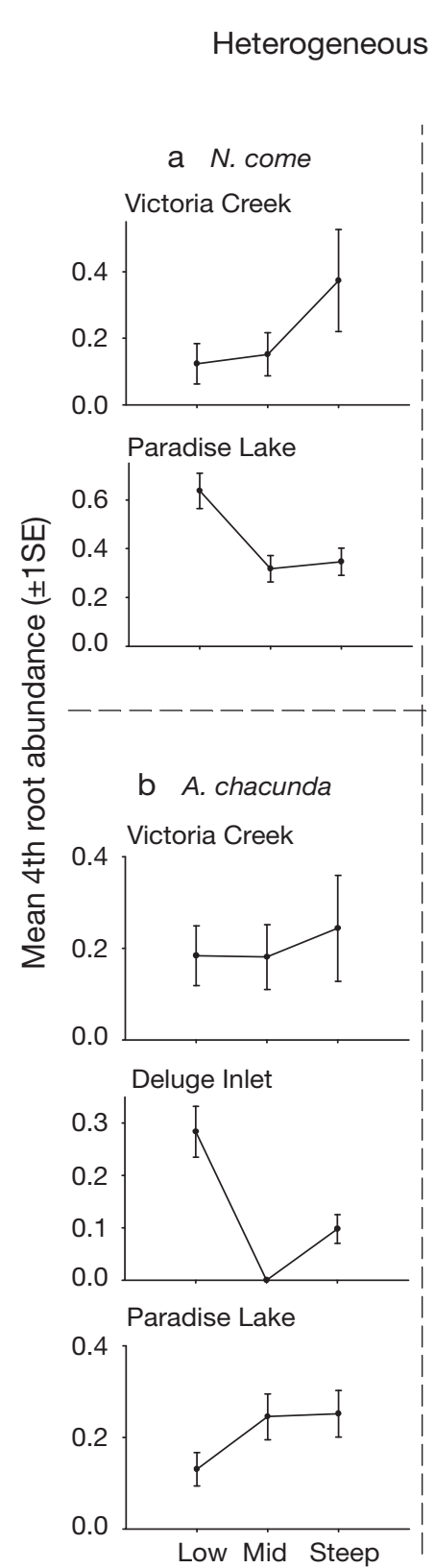

\section{bank profile}

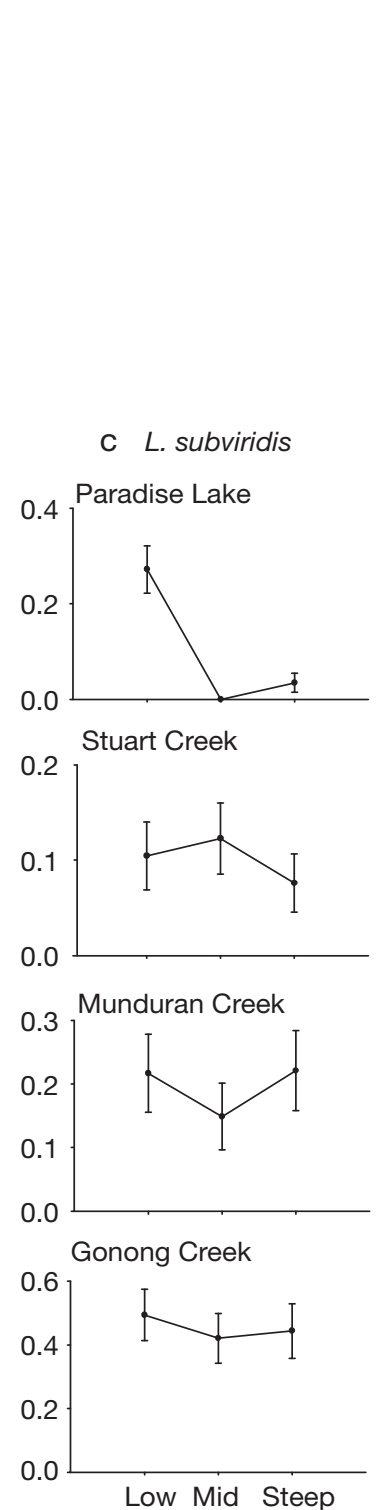

\section{Detrital feeders}

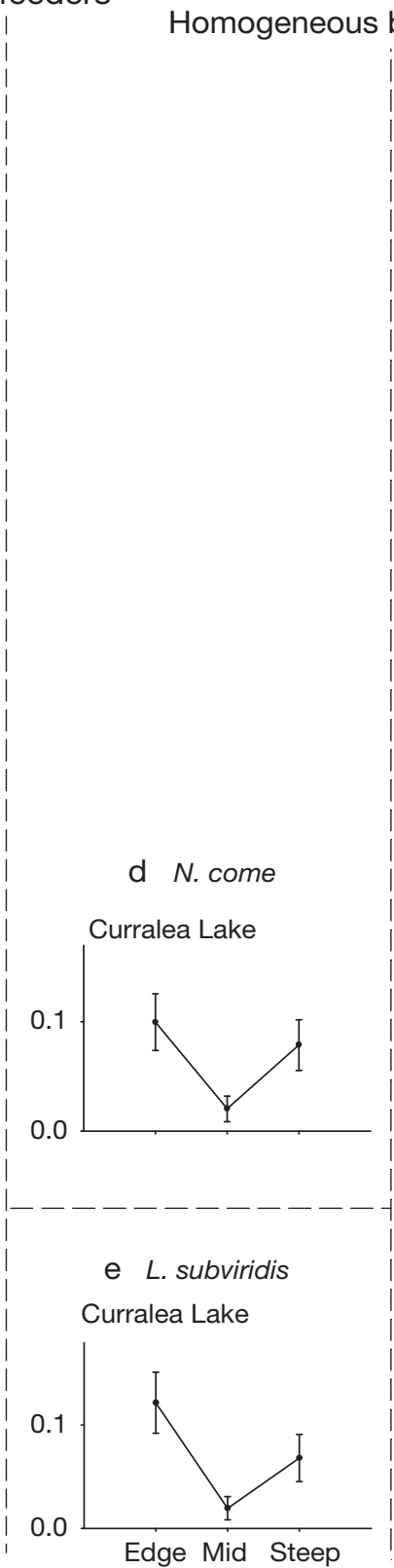

bank profile
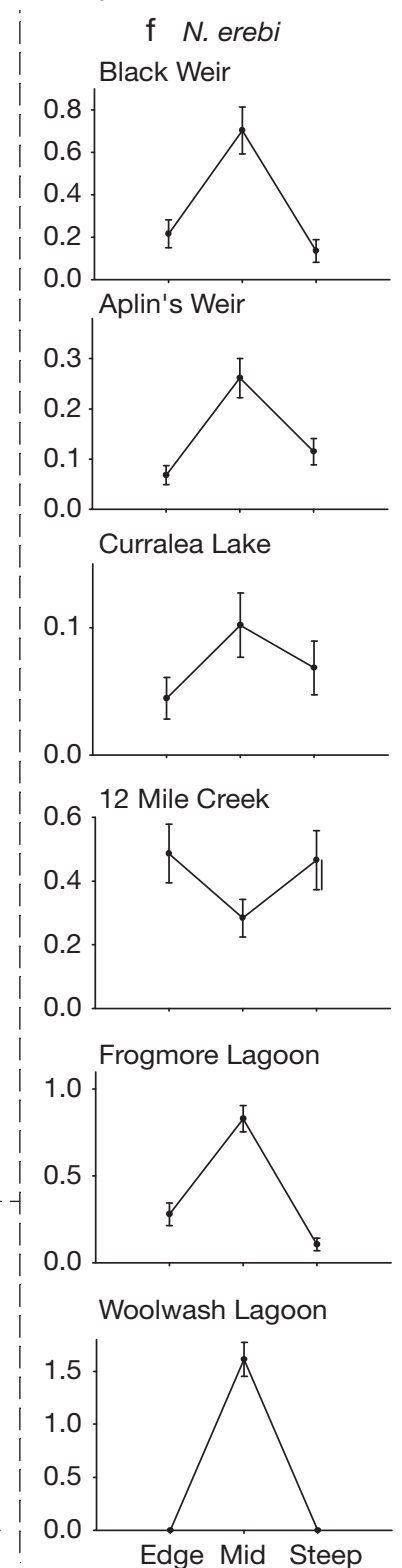

Fig. 11. Cross-channel distribution profiles of mean abundance per net (4th root transformed, \pm SE) for benthivore species in heterogeneous bank profiles (left panels) and homogeneous bank profiles (right panels). For species represented in multiple locations, locations are ranked from deepest to shallowest based on average mid-channel depth. Heterogeneous bank profile: (a) Nematolosa come, (b) Anodontostoma chacunda, (c) Liza subviridis; homogeneous bank profile: (d) N. come, (e) L. subviridis,

(f) N. erebi

\section{Model c: detritivores/homogeneous banks}

A further refinement to the literature-based distribution model was required to accommodate coastal floodplain wetlands inhabited by the highly abundant and widespread detritivore Nematolosa erebi (Fig. 11c). N. erebi are rarely recorded from shallow edges (Johnston \& Sheaves 2006) and were primarily found in mid-channel or deep edge habitats in the present study. $N$. erebi are a major component in the diets of larger piscivorous fishes (Sheaves \& Johnston 2006b) and also appear to be particularly vulnerable to avian predators such as pelicans when deep water is unavailable (Pusey et al. 2004, Sheaves \& Johnston 2006c). In these systems pelicans do not dive to secure prey but are surface feeding predators that take fish by darting their heads into the water while floating on the surface (Derby \& Lovvorn 1997, Kaeding 2002). Consequently, 


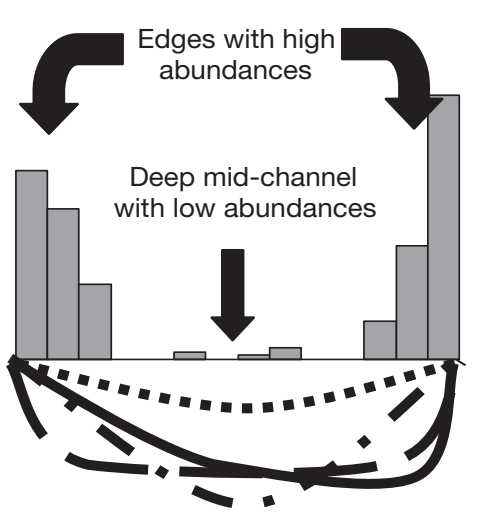

a Pattern of cross-channel distribution of benthivores when mid-channel was deep (mean depth $>0.83 \mathrm{~m}$ ). This pattern was appropriate for all profile shapes (Fig. 3) except for one steep-sided basin, 12 Mile Creek.

C Pattern of cross-channel distribution for detritivores in locations with homogeneous bank profiles and different profile shapes. Detritivores were often abundant on deep edges in steep-sided basins but were predominately in deeper mid-channels when deep water was not available on edges.

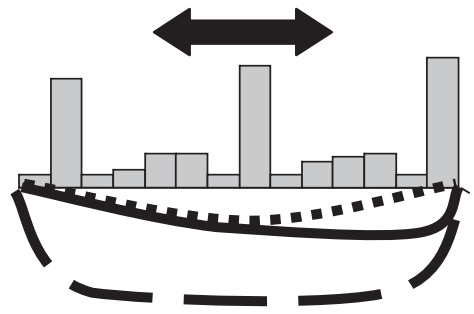

b Pattern of cross-channel distribution for benthivores when mid-channel depth was shallow (mean $<0.83 \mathrm{~m}$ ), and in 12 Mile Creek where mid-channel was deep. In addition, this was the general pattern for planktivores in most locations and detritivores in locations with heterogeneous bank profiles and steep-sided basins irrespective of midchannel depth. This model does not apply to detritivores in freshwater locations.

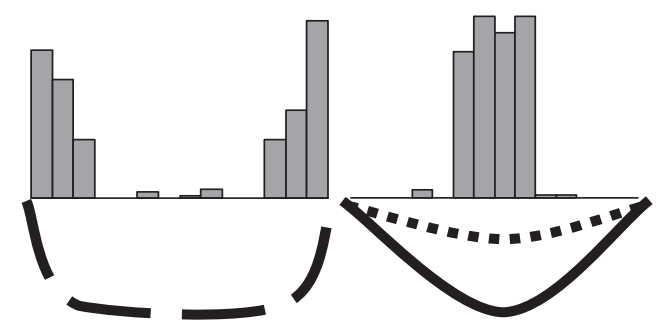

Fig. 12. Revised models of the spatial distribution of fish along cross-channel profiles in tropical and subtropical coastal floodplain wetlands. Generalised distribution models are presented for: (a) benthivores when mid-channel was deep; (b) benthivores when mid-channel was shallow as well as planktivores and detritivores in locations with heterogeneous bank profiles; and (c) detritivores in locations with homogeneous bank profiles

$N$. erebi may gain refuge from pelicans by remaining in deeper water (Pusey et al. 2004, Sheaves \& Johnston 2006c); thus it is likely that predation risk plays an important role in determining the distribution of $N$. erebi and that refuge from surface feeding piscivorous birds is more important than refuge from piscivorous fishes. At the time of sampling there were particularly high densities of pelicans present at Woolwash Lagoon; therefore it seems likely that the distribution patterns observed for all fishes in this location was a response to predation by birds. One consequence of avian predator avoidance is that the shape of crosschannel profiles (Fig. 3) should also influence (at least) $N$. erebi distribution because profile shape primarily defines the distribution of deep water. In the present study, $N$. erebi abundances were higher mid-channel in locations with shallowly-and steeply-sloping edges and higher on edges in steep-sided basins. While some caution is required in interpreting the generality of results from shallowly sloping (1 location) and steepsided (2 locations) profiles, if deep water provides refuge from birds, the use of deep water in conjunction with edges may provide better refuge from predatory fish and diving birds such as cormorants than midchannel areas because the number of directions predators can approach from may be reduced.

\section{CONCLUSIONS}

In the past it seems to have been tacitly assumed that a single conceptual model could be applied to all species and functional groups across different types of estuaries and coastal wetlands. In retrospect, this assumption seems to have been unrealisitic. Indeed, even for relatively species-poor temperate estuaries there is evidence that the generic model was not appropriate for all small fish, with some species using deeper offshore habitats (e.g. Miltner et al. 1995). The existence of a number of different patterns of distribution has obvious implications for tropical estuaries, where a great diversity of fish in all functional groups (Robertson \& Blaber 1992) provides the possibility for complex ecological interactions.

Although the processes underlying the use of shallow water in wetlands are poorly understood, it is clear that access to shallow habitats is important for wetland fish assemblages. The improved understanding of the way small fish are spatially distributed in tropical estuaries and wetlands, provided by this study, has important implications for managers. Shallow margins and shallow intertidal areas are the most modified areas in wetlands and continue to be focal areas for development (canal developments, marinas, land reclamation, aquaculture) 
(Blaber 2002, Bond \& Lake 2005). This reduces the area of shallow water available to fishes, making it likely that many species will be disadvantaged, and valuable nursery function impaired.

Acknowledgements. This project was supported by a grant from the Cooperative Research Centre for Coastal Zone, Estuary and Waterway Management. We thank K. Abrantes, R. Baker, P. Verwey and others for their valuable field assistance.

\section{LITERATURE CITED}

Baker R, Sheaves M (2005) Redefining the piscivore assemblage of shallow estuarine nursery habitats. Mar Ecol Prog Ser 291:197-213

Baker R, Sheaves M (2006) Visual surveys reveal high densities of large piscivores in shallow estuarine nurseries. Mar Ecol Prog Ser 323:75-82

Blaber SJM (1980) Fish of the Trinity Inlet system of north Queensland with notes on the ecology of fish faunas of tropical Indo-Pacific estuaries. Aust J Mar Freshw Res 31:137-146

Blaber SJM (2002) 'Fish in hot water': the challenges facing fish and fisheries research in tropical estuaries. J Fish Biol 61:1-20

Blaber SJM, Young JW, Dunning MC (1985) Community structure and zoogeographic affinities of the coastal fishes of the Dampier Region of north-western Australia. Aust J Mar Freshw Res 36:247-266

Blaber SJM, Brewer DT, Salini JP (1989) Species composition and biomasses of fishes in different habitats of a tropical northern Australian estuary: their occurrence in the adjoining sea and estuarine dependence. Estuar Coast Shelf Sci 29:509-531

Bond NR, Lake PS (2005) Ecological restoration and largescale ecological disturbance: the effects of drought on the response by fish to a habitat restoration experiment. Restor Ecol 13:39-48

Breiman L, Friedman J, Olshen R, Stone C (1984) Classification and regression trees. Wadsworth International Group, Belmont, CA

Cain RL, Dean JM (1976) Annual occurrence, abundance and diversity of fish in a South Carolina intertidal creek. Mar Biol 36:369-379

Coles RG, Lee Long WJ, Watson RA, Derbyshire KJ (1993) Distribution of seagrasses, and their fish and penaeid prawn communities, in Cairns harbour, a tropical estuary, Northern Queensland, Australia. Aust J Mar Freshw Res 44:193-210

Cross TK, McInerny MC (2005) Spatial habitat dynamics affecting bluegill abundance in Minnesota bass-panfish lakes. N Am J Fish Manag 25:1051-1066

DAFF (Department of Agriculture Fisheries and Forestry) (2007) Seaweek: marine bycatch matters. Available at: www.mesa.edu.au/ seaweek2007

De'ath G (2002) Multivariate regression trees: a new technique for modeling species-environment relationships. Ecology 83:1105-1117

De'ath G, Fabricius KE (2000) Classification and regression trees: a powerful yet simple technique for ecological data analysis. Ecology 81:3178-3192

$>$ Derby CE, Lovvorn JR (1997) Predation on fish by cormorants and pelicans in a cold-water river: a field and modeling study. Can J Fish Aquat Sci 54:1480-1493

Ellis WL, Bell SS (2004) Conditional use of mangrove habitats by fishes: depth as a cue to avoid predators. Estuaries 27:966-976

Gaudin P, Sempeski P (2001) The role of river bank habitat in the early life of fish: the example of grayling, Thymallus thymallus. Int J Ecohydrol Hydrobiol 1:203-208

Gibson RN, Robb L, Wennhage H, Burrows MT (2002) Ontogenetic changes in depth distribution of juvenile flatfishes in relation to predation risk and temperature on a shallow-water nursery ground. Mar Ecol Prog Ser 229: 233-244

Isaak DJ, Thurow RF (2006) Network-scale spatial and temporal variation in chinook salmon (Oncorhynchus tshawytscha) redd distributions: patterns inferred from spatially continuous replicate surveys. Can J Fish Aquat Sci 63:285-296

Johnston R, Sheaves M (2006) Within-pool distribution of aquatic vertebrates. In: Sheaves M, Collins J, Houston W, Dale P, Revill A, Johnston R, Abrantes K (eds) Contribution of floodplain wetland pools to the ecological functioning of the Fitzroy River Estuary. Cooperative Research Center for Coastal Zone, Estuarine and Waterway Management, Brisbane

Johnston R, Sheaves M (2007) Small fish and crustaceans demonstrate a preference for particular small-scale habitats when mangrove forests are not accessible. J Exp Mar Biol Ecol 353:164-179

Johnston R, Sheaves M, Molony B (2007) Are distributions of fishes in tropical estuaries influenced by turbidity over small spatial scales? J Fish Biol 71:657-671

Kaeding LR (2002) Factors influencing the distribution of American white pelicans foraging on the Yellowstone River, Yellowstone National Park, USA. Waterbirds 25: 305-311

Krumme U, Saint-Paul U, Rosenthal H (2004) Tidal and diel changes in the structure of a nekton assemblage in small intertidal mangrove creeks in northern Brazil. Aquat Living Resour 17:215-229

Mallin MA, Lewitus AJ (2004) The importannce of tidal creek ecosystems. J Exp Mar Biol Ecol 298:145-149

McCune B, Grace JB (2002) Analysis of ecological communities. MjM Software Design, Gleneden Beach, OR

McIvor CC, Odum WE (1988) Food, predation risk, and microhabitat selection in a marsh fish assemblage. Ecology 69:1341-1351

Miltner RJ, Ross SW, Posey MH (1995) Influence of food and predation on the depth distribution of juvenile spot (Leiostomus xanthurus) in tidal nurseries. Can J Fish Aquat Sci 52:971-982

Morton RM, Pollock BR, Beumer JP (1987) The occurrence and diet of fishes in a tidal inlet to a saltmarsh in southern Moreton Bay, Queensland. Aust J Ecol 12:217-237

Paterson AW, Whitfield AK (2000) The ichthyofauna associated with an intertidal creek and adjacent eelgrass beds in the Kariega Estuary, South Africa. Environ Biol Fishes 58:145-156

Pusey BJ, Kennard MJ, Arthington AH (2004) Freshwater fishes of north-eastern Australia. CSIRO Publishing, Collingwood

Reis RR, Dean JM (1981) Temporal variation in the utilization of an intertidal creek by the bay anchovy (Anchoa mitchilli). Estuaries 4:16-23

Robertson AI, Blaber SJM (1992) Plankton, epibenthos and fish communities. In: Robertson AI, Alongi DM (eds) Tropical mangrove ecosystems. American Geophysical Union, Washington, DC 
Robertson AI, Duke NC (1987) Mangroves as nursery sites: comparisons of the abundance and species composition of fish and crustaceans in mangroves and other nearshore habitats in tropical Australia. Mar Biol 96: 193-205

Robertson AI, Duke NC (1990) Mangrove fish-communities in tropical Queensland, Australia: spatial and temporal patterns in densities, biomass and community structure. Mar Biol 104:369-379

Ruiz GM, Hines AH, Posey MH (1993) Shallow water as a refuge habitat for fish and crustaceans in nonvegetated estuaries: an example from Chesapeake Bay. Mar Ecol Prog Ser 99:1-16

Sheaves MJ (1992) Patterns of distribution and abundance of fishes in different habitats of a mangrove-lined tropical estuary, as determined by fish trapping. Aust J Mar Freshw Res 43:1461-1479

Sheaves MJ (1996) Habitat-specific distributions of some fishes in a tropical estuary. Mar Freshw Res 47:827-830

Sheaves M (2001) Are there really few piscivorous fishes in shallow estuarine habitats? Mar Ecol Prog Ser 222: 279-290

Sheaves M (2005) Nature and consequences of biological connectivity in mangrove systems. Mar Ecol Prog Ser 302:293-305

Sheaves M (2006) Scale-dependent variation in composition of fish fauna among sandy tropical estuarine embayments. Mar Ecol Prog Ser 310:173-184

Sheaves M, Johnston R (2006a) The influence of connectivity on patterns of composition and density of fish from Fitzroy wetland pools. In: Sheaves M, Collins J, Houston W, Dale P, Revill A, Johnston R, Abrantes K (eds) Contribution of floodplain wetland pools to the ecological functioning of the Fitzroy River estuary. Cooperative Research Center for Coastal Zone, Estuarine and Waterway Management, Brisbane

Editorial responsibility: Matthias Seaman, Oldendorf/Luhe, Germany
Sheaves M, Johnston R (2006b) Diets of fish from Fitzroy wetland pools. In: Sheaves M, Collins J, Houston W, Dale P, Revill A, Johnston R, Abrantes K (eds) Contribution of floodplain wetland pools to the ecological functioning of the Fitzroy River estuary. Cooperative Research Center for Coastal Zone, Estuarine and Waterway Management, Brisbane

Sheaves M, Johnston R (2006c) Spatio-temporal patterns of fish condition. In: Sheaves M, Collins J, Houston W, Dale P, Revill A, Johnston R, Abrantes K (eds) Contribution of floodplain wetland pools to the ecological functioning of the Fitzroy River estuary. Cooperative Research Center for Coastal Zone, Estuarine and Waterway Management, Brisbane

Sheaves M, Molony B (2000) Short-circuit in the mangrove food chain. Mar Ecol Prog Ser 199:97-109

Sheaves M, Collins J, Houston W, Dale P, Revill A, Johnston R, Abrantes K (2006) Contribution of floodplain wetland pools to the ecological functioning of the Fitzroy River estuary. Cooperative Research Center for Coastal Zone, Estuarine and Waterway Management, Brisbane

Sheaves M, Abrantes K, Johnston R (2007aa) Nursery ground value of an endangered wetland to juvenile shrimps. Wetlands Ecol Manag 15:311-327. Available at: www. springerlink.com/content/g488j27268241571/fulltext.pdf

Sheaves M, Johnston RW, Abrantes KGS (2007b) Fish fauna of dry tropical and sub-tropical estuarine floodplain wetlands. Mar Freshw Res 58:941-943

Stevens PW, Montague CL, Sulak KJ (2006) Patterns of fish use and piscivore abundance within a reconnected saltmarsh impoundment in the northern Indian River Lagoon, Florida. Wetlands Ecol Manag 14:147-166

Wilson JP, Sheaves M (2001) Short-term temporal variations in taxonomic composition and trophic structure of a tropical estuarine fish assemblage. Mar Biol 139:787-796

Submitted: June 5, 2007; Accepted: October 23, 2007 Proofs received from author(s): March 11, 2008 